\title{
Rainfall Harvesting as Resources of Self Watering Fertigation System with Various Growing Medias
}

\author{
Nurpilihan Bafdal $^{\#}$ \\ \# Soil and Water Engineering Padjadjaran University, Jl Raya Bandung-Jatinangor, 40600, Indonesia \\ E-mail: nurpilihanbafdal@yahoo.com
}

\begin{abstract}
The climate condition in Indonesia determinate by tropical monsoons, in normal years the rainy season extend about 6 months, from November to April and the dry season prevails from May to September. The annual rainfall is more less $2000 \mathrm{~mm}$, of which more than $80 \%$ occur in rainy season. In dry season has a critical water deficit to crops while during the wet season, water from rainfall is able to collect it to storage and applied as irrigation water especially in the dry season. The problem is could the rainfall harvesting roof top of the greenhouse good enough for crop water requirement with various growing medias during dry and wet seasons. Self watering fertigation is a system was water irrigation mixed with fertilizer and applied it to the autopots simultaneously through the closed channel. The study of rainfall harvesting as a resources of self water fertigation with various growing medias were the first year from 4 years of the main research with topic supply and demand water management on self watering fertigation system. The research funding born from Academic Leadership Grant (ALG) 1.1.6. The objective of the first research were to find out conducted for each three treatments of growing medias and consumptive used. The experiment was conducted in Jatinangor, West Java Indonesia with treatments were water requirement efficiency and three growing medias i.e. (1) paddy skin charcoal with compos; (2) paddy skin charcoal with organic matter and (3) paddy skin charcoal with coco peat. Cherry tomato and paprika were planted. The results show that water requirement efficiency with growing media of paddy skin charcoal with compos gave growth and production for cherry tomato and paprika.
\end{abstract}

Keywords — Rainfall Harvesting; Self Watering System; Autopot; Fertigation; growing medias; paddy skin charcoal

\section{INTRODUCTION}

In many developing countries, agriculture is still the main user land and water resources. The challenges of the future of the land due to most people live on the land, from the land and with the land [1], so land has always been: (i) a source of minerals, fertilizer and renewable energy[2]; (ii) influence by climate change; (iii) source of water, food, fibre and biodiversity[1], [2] and (iv) living and working space for man and infrastructural needs for requirements. The function of growing medias planning is to guide decisions on future land use in such a way the land resources are put to the most beneficial use for man while at the same time conserving land used planning for agriculture [2].

Indonesia has a heavy rainfall were annual rainfall more less $2000 \mathrm{~mm}$, of which more than $80 \%$ occur in rainy season[3]. In addition as a source of rainfall water for crops is well known as a good source of irrigation[4]. The distribution and accumulation of water from rainfall vary with the dry and wet seasons were in dry season has a critical water deficit to crops while in the wet season crops water requirement are good enough and is estimated to be crops growth on $100 \%$ of the total cultivated[5].
Supply water from rainfall is able to collect it to storage such as ponds or torrents and applied it as irrigation water especially in the dry season. Generally in the amount of rainfall is to be not the same for different location because depending of numerous factors may affect including rainfall duration; rainfall intensity and rainfall distribution. Harvested rainwater is used as sources of irrigation water in hydroponic crops are cultivated using self watering fertigation system. Fertigation is a method of fertilizer application in which fertilizer is incorporated within the irrigation water. In this system fertilizer solution is distributed evenly in irrigation. Self-watering system is one model system of water and fertilization system automatically without electrical energy to the plant. Water and nutrients that plants need is given to individuals within the system installation that's unique using independent and portable device, call it Autopot. Figure 1 below shown the picture of plant and autopot plotting with small torrent for fertigation in the greenhouse. 


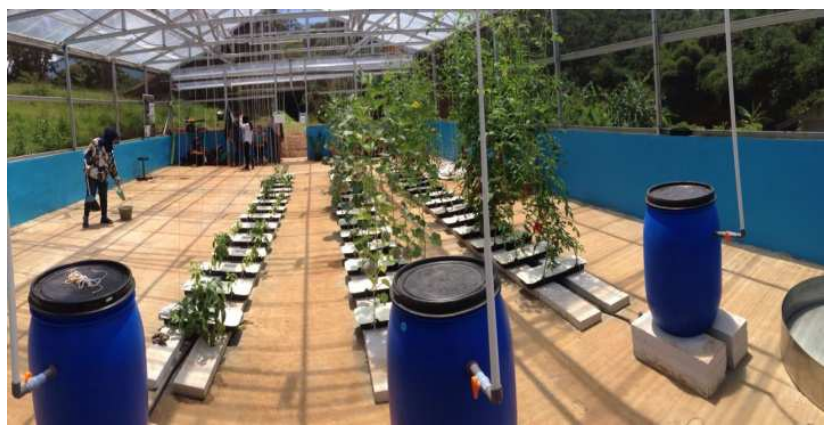

Fig. 1 Autopot, fertigation in small torrents and plants in greenhouse

To solved a problem of availability of water is limited for crops and long dry season were to manage a rainfall harvesting during wet season saved and applied it as an irrigation in order the needs of crops water requirement.

All agricultural activities are assumed to be sustainable, for greenhouse farming activities sustainable of water and nutrient elements, i.e. the total store of each of the macro elements and micro elements in growing medias is assumed to be constant. Applied of fertigation will contribute to increased horticulture productivity such as cherry tomato and paprika. Increased crops production may be achieved through of technological development such as self-water fertigation system based on rainfall harvesting. Therefore, for a sustainable fertigation of a supply to the crops are a major strategies reason for save employers, save also energy of electricity and one of planning at the farm level and give the farmer's welfare to marginalization of rural areas.

The study of rainfall harvesting as a resources of selfwater fertigation with various growing medias were the first year from 4 years of the main research with topic supply and demand water management on self-watering fertigation system. The research funding born from Academic Leadership Grant (ALG) 1.1.6. The objective of the this research were to find out conducted for each three treatments of growing medias and consumptive used.

\section{A. Autopot Technology with Smartvalve}

Autopot technology is an efficient and environmentallyfriendly technology that revolves around the smartvalve, which feeds plants on demand. The eco-friendly Autopot system allow for sustainable and consistent crop cultivation which in independent of soil, fed with nutrient-rich water, crop are protected from soil born disease and kept healthy without the use of harmful chemical[6]

How does it work? (1) When the smartvalve is connected to water supply, the bottom float will allow water through the inlet; (2) As the water level goes up, the water level around the smart valve rises but not in the cavity of the smartvalve in the bottom float remains in the resting position; (3) once the water level lift the top float, water level fill the smart valve cavity and the bottom float will rise, then preventing any more water from flowing in; (4) As the plant(s) feed, the water level will begin to drop again; (5) when the water is fully consumed, the bottom float will fall back to its original position, causing the inlet to open and allow water into the system again.

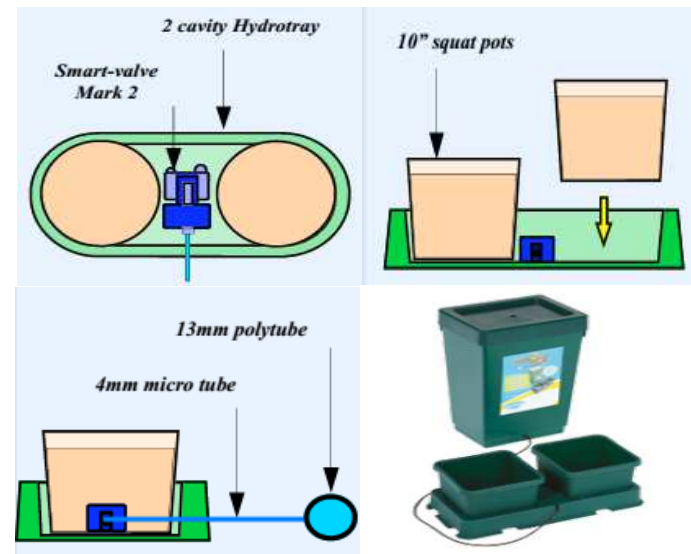

Fig 2. Self Watering System Device

There are some benefit of the Autopot Technology System, these are [6]:

1. Resource efficiency, there is no water wastage or nutrient run-off as plant feed on demand

2. Environmentally friendly, without nutrient runoff there is no pollution to surrounding water systems

3. Flexibility, the system allows for agriculture to thrive in areas that would normally be seen as nonconductive to farming such as non-productive as marginal land or even rooftop

4. Automated and simple, this system is fully automated farming on a commercial scale becomes easier and less labours

5. Consistent, crop yield quality and quantity are consistent

\section{MATERIALS AND METHODS}

The research was conducted in greenhouse at Jatinangor, Sumedang West Java Indonesia with medium altitude of 745 meter above sea level. All crops and growing medias growth on autopots with used the valve to control the water and applied fertigation automatically, while the water came from harvesting rainfall were collecting from torrents outside the greenhouse. Potential rainfall was harvested from roof top of the greenhouse and collect it to the two big torrents outside the greenhouse, and applied it as self-watering fertigation to the autopots, the each torrent content were 5300 litres.

Cherry tomato and paprika were planted, with three growing medias these are (1) combination of paddy skin charcoal with compos; (2) paddy skin charcoal with organic matter and (3) paddy skin charcoal with coco peat. The treatments of the growing medias were $50 \%$ in height of autopot paddy skin charcoal combination with the $50 \%$ other medias respectively i.e. :

M1 : paddy skin charcoal with compos; in growing medias weight are paddy skin charcoal were 230 grams mixed with compos are 878 grams;

M2 : paddy skin charcoal with organic matter; in growing medias weight are. Paddy skin charcoal was 230 grams mixed with organic matter are 720 grams.

M3 : paddy skin charcoal with cocopeat; in growing medias weight are paddy skin charcoal were 230 grams mixed with cocopeat 235 grams. Each autopots consisted two plants. 
Crop water consumption measured is done by calculating the total loss of water from the torrent of nutrients. Measurement of the amount of water consumed is done every day. Moreover, the choice of the best planting medium is also based on crop production, by measuring the total weight of the harvest.

\section{RESULTS AND DISCUSSION}

\section{A. Growing Media Physical Characteristic}

The parameters were tested to determine the physical characteristics of growing media that is associated with Bulk Density, moisture content, specific gravity, porosity, and permeability. The test results can be viewed pad Table 1 .

Planting medium used in this study is an organic growing media are readily available and inexpensive, such as husk charcoal, humus and compost. Besides planting medium should also have a high porosity values but also can withstand water / nutrients longer. This is caused, in principle autopot system using capillary irrigation system or subsurface irrigation systems.
Based on Table 1, data of water content, water content ratio of the dry weight of the planting medium should be balanced i.e. the ratio between water and dry land, based on analysis of data on the water content of M1 with a value of $54.9 \%$ compared with the balanced approach of growing media M2 with a value of $59.8 \%$ and M3 amounted to $73.1 \%$. The value of bulk density that is M1 with a value of $0.53 \mathrm{~g} / \mathrm{cc}$ then M2 $0.46 \mathrm{~g} / \mathrm{cc}$ and M3 of $0.21 \mathrm{~g} / \mathrm{cc}$. The weight of the contents of the M3 have the low value it means that the amount of solids can cause less porous planting medium is high, so that the water content in M3 was higher than the planting medium, this too can cause the growth of plants that are not optimal because it can happen root rot in plants, It is inversely proportional to the conditions on the M1, M2 and growing media that have a more optimal growth. Value of specific gravity (specific gravity), M1 with a value of $1.71 \mathrm{~g} / \mathrm{cc}, \mathrm{M} 21.62 \mathrm{~g} / \mathrm{cc}$, and M3 amounted to $1.48 \mathrm{~g} / \mathrm{cc}$. The specific gravity of the M1 has a higher value so that the amount of solids to the absorption of nutrients in decomposing nutrients better than the M2 and M3. Specific gravity is associated with bulk density and total pore space.

TABLE I

GROWING MEDIA PHYSICAL CHARACTERISTIC

\begin{tabular}{|c|c|c|c|c|c|c|c|c|c|}
\hline \multirow{2}{*}{$\begin{array}{c}\text { Growing } \\
\text { Media }\end{array}$} & \multirow{2}{*}{$\begin{array}{c}\text { Bulk } \\
\text { Density } \\
\text { g/cc }\end{array}$} & \multirow{2}{*}{$\begin{array}{c}\text { Specific } \\
\text { Gravity } \\
\text { g/cc }\end{array}$} & \multirow{2}{*}{$\begin{array}{l}\text { Total Pores } \\
\text { (\% vol) }\end{array}$} & \multicolumn{2}{|c|}{$\begin{array}{c}\text { Drainage Pores } \\
(\% \text { Volume })\end{array}$} & \multirow{2}{*}{$\begin{array}{c}\text { Available } \\
\text { Water Content } \\
\text { (\% Vol) } \\
\end{array}$} & \multirow{2}{*}{$\begin{array}{l}\text { Permeability } \\
\text { (cm/hour) }\end{array}$} & \multirow{2}{*}{\multicolumn{2}{|c|}{$\begin{array}{l}\text { Water Conten } \\
\text { (\% vol) }\end{array}$}} \\
\hline & & & & Rapid & Slow & & & & \\
\hline \multirow{4}{*}{ M1 } & \multirow{4}{*}{0,53} & \multirow{4}{*}{1,71} & \multirow{4}{*}{69,3} & \multirow{4}{*}{25,3} & \multirow{4}{*}{5,7} & \multirow{4}{*}{21,3} & \multirow{4}{*}{16,54} & $\mathrm{pF} 1$ & $=51.3$ \\
\hline & & & & & & & & $\mathrm{pF} 2$ & $=44$ \\
\hline & & & & & & & & $\mathrm{pF} 2.54$ & $=38.3$ \\
\hline & & & & & & & & $\mathrm{pF} 4.2$ & $=17$ \\
\hline \multirow{4}{*}{ M2 } & \multirow{4}{*}{0,46} & \multirow{4}{*}{1,62} & \multirow{4}{*}{71,6} & \multirow{4}{*}{31,6} & \multirow{4}{*}{5,4} & \multirow{4}{*}{18,7} & \multirow{4}{*}{6,73} & $\mathrm{pF} 1$ & $=52.5$ \\
\hline & & & & & & & & $\mathrm{pF} 2$ & $=40$ \\
\hline & & & & & & & & $\mathrm{pF} 2.54$ & $=34.6$ \\
\hline & & & & & & & & $\mathrm{pF} 4.2$ & $=15.9$ \\
\hline \multirow{4}{*}{ M3 } & \multirow{4}{*}{0,21} & \multirow{4}{*}{1,48} & \multirow{4}{*}{85,8} & \multirow{4}{*}{51,4} & \multirow{4}{*}{4,8} & \multirow{4}{*}{15,7} & \multirow{4}{*}{15,29} & $\mathrm{pF} 1$ & $=63.7$ \\
\hline & & & & & & & & $\mathrm{pF} 1$ & $=34.3$ \\
\hline & & & & & & & & $\mathrm{pF} 2.54$ & $=29.5$ \\
\hline & & & & & & & & $\mathrm{pF} 4.2$ & $=13.8$ \\
\hline
\end{tabular}

Crops medias such as skin paddy charcoal; humus; organic matter and cocopeat are the most consistent feature of land use planning or new land resources. In Indonesia especially in West Java most of the farmers in rural are solely dependent on agriculture for their income. For farmers in rural and also in urban people with only small areas of their own land the technology of rainfall harvesting and applied it as a fertigation (irrigation mixed with fertilizer) to autopot in greenhouse as an alternative of land management on horticultural crops grown. The growing medias are suitable for a number of horticultural crops and water for fertigation has to be available; since greenhouse horticulture uses relatively small plots of land [9].

Selected of crops medias has been promoted as a rational way to manage growing medias resources; but often expectation have been disappointed. The most consistent feature of selected land use planning like the crops medias very depends on condition of growing medias; information based of research; any crops growth and available growing medias in the research areas [9]-[11].

Charcoal is receiving a growing interest as a sustainable technology to improved soil fertility and crop growth. Charcoal soil additions cause increases in soil $\mathrm{pH}$ from 4,59 to 5,83) and increased nutrients $\mathrm{C}$ ( from 3,94 to 15 gram); and exchangeable $\mathrm{K}$ ( from 0,016 to $0,052 \mathrm{C} \mathrm{mol} \mathrm{kg-1)} \mathrm{[12].}$

Compost is organic matter that has been composed and recycled as a fertilizer and soil amendment. Compost is rich in nutrient; it is used in horticulture and agriculture. The compost itself is beneficial for land in many ways, including as a soil conditioner; a fertilizer [10]. Organic matters present throughout the ecosystem; were the organic matter not already in the soil comes from ground water. Definition of organic matter is biological material in process of decaying or decomposition such as humus.

Coco peat is an agricultural by-product obtained after the extraction of fibber from the coconut husk. Cocopeat has 
been recognized to have high water holding capacity which causes poor air-water relationship, leading to low aeration within the medium, thus affecting the oxygen diffusion to the roots [13]-[15].

\section{B. Rainfall vs. Water Consumptive}

The major source of water available either for agriculture or human consumption is obtained from the rainfall that falls on the earth surface. In the humid tropic countries like Indonesia with amount of annual rainfall more than 2000 $\mathrm{mm} /$ year, floods have been damaging problems during the wet season. Rainfall in Indonesia varies from places to places and year to year. Water requirements of different crops also vary widely depending of the type of soil, growing medias and growing plant or growing plant period. The best way to control floods is to collect rainfall to storage reservoirs such as ponds and torrents and applied it as irrigation to the crops.

Irrigation is an artificial application of water to the soil or growing medias for the purpose of crop production. The increasing need for crop production for the growing population is causing the rapid expansion of irrigation. Figure 2 below shown the volume rainfall harvesting during the research done.

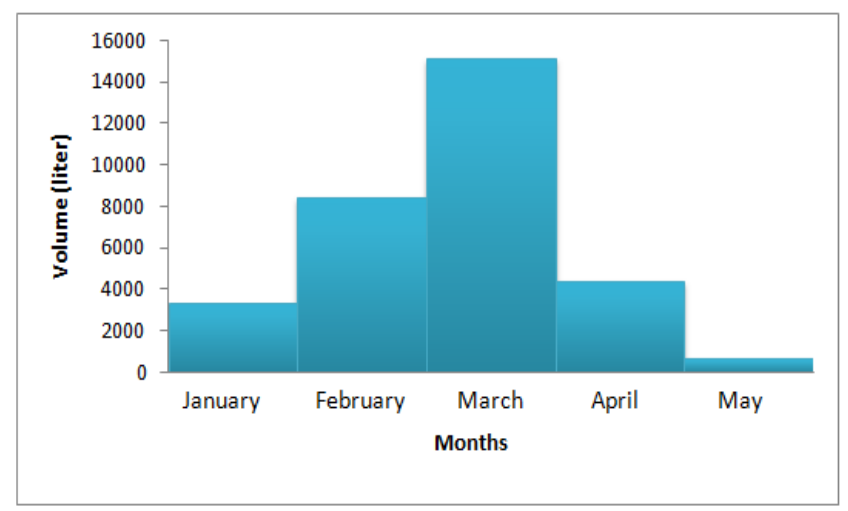

Fig 2. Rainfall Harvesting (months/litres)

Figure 2 shows that the highest amount of rainfall harvesting were on March (15000 litres) and the lowest were on May only 600 litres). The amount of water harvesting during research from the beginning to harvest were 31200 litres. The amount of rainfall harvesting from data above are very high compared with numbers of plants growth (paprika and cherry tomato) were planting in the greenhouse (numbers of paprika and cherry tomato were 28 respectively).

Figure 3 below shows that water consumptive of paprika plants with three treatments of growing medias. The treatment M1 were the highest water consumptive if compared with the other two treatments of growing medias; while treatment M3 were a lowest of water consumptive used. Water consumptive used on February; March and April were not significant, but not for on May water consumptive decreased significantly; the reason is on May growth developed of paprika were finished and only need less water consumptive used.

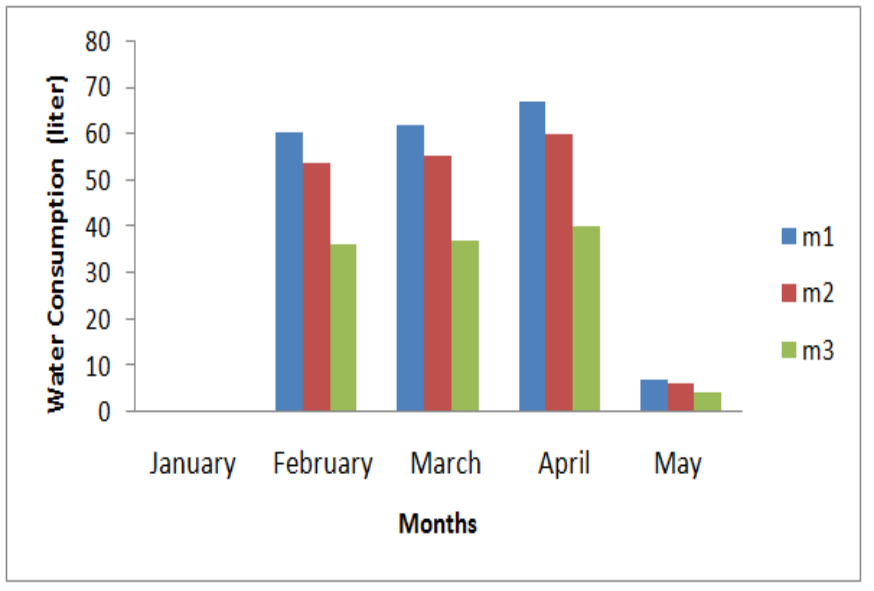

Fig 3. Water consumptive of Paprika

Figure 4 below shows the consumptive use of cherry tomato with vary treatment of growing medias (M1; M2 and M3). In the beginning planting cherry tomato need minimal water consumptive used; but water consumptive used increased significantly with the developed of growing period until of the end of harvesting [7], [8]. The highest water consumptive used were on April; which M1 (450 litres); M2 (400 litres) and M3 (260 litres). The reason is on April were the highest of fruits of tomato cherry; and need more water consumptive used. Harvesting of cherry tomato were 15 time and production of cherry tomato with treatment M1 were more less $5 \mathrm{~kg} /$ plant.

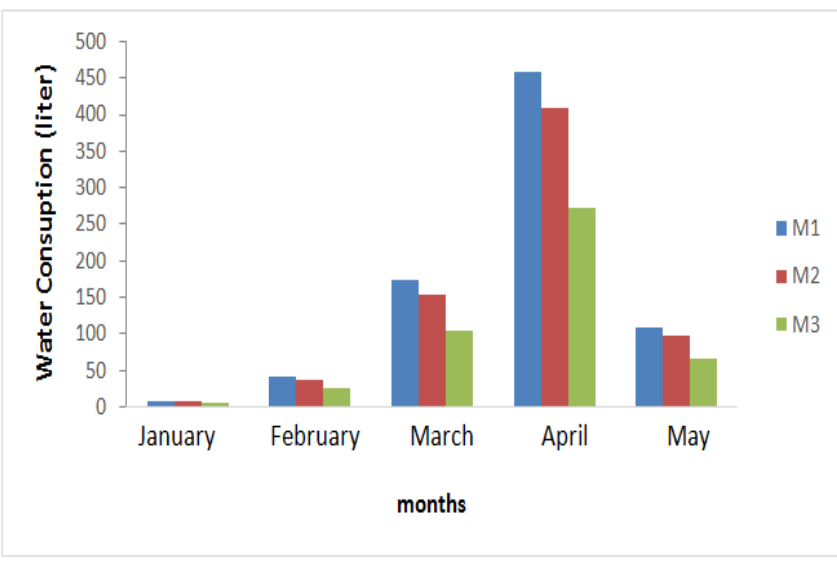

Fig 4. Water consumptive of Tomato Cherry

\section{Cherry Tomato Production}

The cherry tomato production was to be characterised by attainable yield level for a number of indicator crops. Production of a cherry tomato depends on combination of growing medias, and its assessment is achieved by applying on growing medias. The choice of growing medias depends of the medias were available in the research location and also depends of research information requirements of the user of the evaluation results based on research. Table 2 below shows the cherry tomato production with various growing medias. 
TABLE II

CHERry TOMATO PRODUCTION WiTH VARIOUS GROWING MEDIAS

\begin{tabular}{|c|c|}
\hline Growing medias & $\begin{array}{c}\text { Cherry tomato Production } \\
\text { (kg/crop) }\end{array}$ \\
\hline M1 & 4,75 \\
\hline M2 & 2,50 \\
\hline M3 & 0,50 \\
\hline
\end{tabular}

Note:

M1 : Combination of paddy skin charcoal with compos

M2 : Combination of paddy skin charcoal with organic matter

M3 : Combination of paddy skin charcoal with coco peat

Table 2 above shows that the results of cherry tomato production with growing media paddy skin charcoal were the best results if compared with production of cherry tomato with other crops medias. The combined of growing media M1 has results on the most good condition it appeared that the most suited climate such as temperature were in research area. If estimated a numbers of one hectare tomato cherries 8000 plants so the production of cherry tomato with growing media M1 were 38 ton/ha.

The productions of treatment of M3 show very low results $(0,50 \mathrm{~kg} / \mathrm{crop}$ or $4 \mathrm{ton} / \mathrm{ha})$; and some plants were dies on between 15 to 20 days. The results of the growing media evaluated study were coco peat still in decomposition process and gave impact on crops developed, which is there is a water competition between cherry tomato crops with coco peat and the process of the coco peat decomposition give results a high energy and impact it of growing medias and crops developed.

Treatment M2 gave a good results if compared with M3 but it treatment not significantly effect on M1; during growth period until harvested of cherry tomato no one crops indicated died.

\section{Paprika Production}

The effect of several growing medias use were assisted in the paprika crop. Selected of the growing medias situations are examples of what can be achieved in term of food production, income and employments. The assessment of growing medias based on selected of growing medias for instant available enough in the research areas; limited employments; available of water resources for irrigation; opportunities of seasons (dry season or wet season) and estimated of good growing and high production of crops. Table 3 below shows the production of paprika with various growing medias.

TABLE III

PAPRIKA’s PRODUCTION WITH VARIOUS CROP MEDIAS

\begin{tabular}{|c|c|}
\hline Growing medias & $\begin{array}{c}\text { Paprika's production } \\
\text { (Kg/plant) }\end{array}$ \\
\hline M1 & 1,3 \\
\hline M2 & 1,5 \\
\hline M3 & 0,8 \\
\hline
\end{tabular}

M1: combination of paddy skin charcoal with compos

M2: combination of paddy skin charcoal with organic matter

M3: combination of paddy skin charcoal with cocopeat
Table 3 above shows that treatment M2 gave a highest production of paprika compared between two alternative M1 and M3. The main reasons are the organic matter in which influenced of the growing and paprika production. Combination between paddy skin charcoal and organic matter as a growing medias of paprika and available of self fertigation simultaneously effective use of growing and paprika production. If estimated a number of paprika plants were $20000 / \mathrm{ha}$, it will be a 30 ton paprika production/ha. Treatment of M3 gave the lowest paprika production; and $7 \%$ of the paprika crops were dies during the crops growth. The main reason which is cocopeat were still decomposition process and make a high energy, it will impact to growing and paprika production.

No significantly affect between treatment M1 and M2 on paprika production, but treatment M2 still gave the best paprika production. In Indonesia paprika is a high economic crop and it consumed for people a middle level to high level. Nowadays the price it were Rp 40000/kg to Rp 50000/kg.

\section{CONCLUSIONS}

Based on the research results, it could be concluded that treatment of combination between paddy skin charcoal with compos (M1) gave good growth developed of plants and the highest cherry tomato production with compared with other growing medias. The treatment of combination of paddy skin charcoal with organic matter (M2) gave good the growth developed of plants and the highest paprika production with compared with other growing medias. Paprika show that the water consumptive used for three treatment of growing medias not significantly effect on February, March and April but decreased significantly on May. Cherry tomato show that the highest water consumptive on April were the highest cherry tomato fruits.

\section{ACKNOWLEDGMENT}

We are most gratefully to Professor Tri Hanggono Achmad as a Rector of Padjadjaran University for His many insightful ideas and suggestions during the research; and funding born from Academic Leadership Grant (ALG) 1.1.6.

\section{REFERENCES}

[1] Food and Agriculture Organization of the United Nations (FAO) and United Nations Environment Programme (UNEP), The Future of Our Land. Facing the Challenge. Rome, Italy, 1999.

[2] D. J. Sailor and M. Hagos, "growing media," Energy Build., pp. 1-6, 2011

[3] N. Bafdal, S. Dwiratna, and D. R. Kendarto, "Runoff Managemen Technology for Integrated Dry Land Agriculture in Jatinangor Research Center West Java Indonesia,” Egypt. J. Desert Res., vol. 65, pp. 1-11, 2015.

[4] S. Dwiratna, D. R. Kendarto, and N. Bafdal, "Study of Rainwater Harvesting Potential in Jatinangor," in Proceedings of the 2015 PERTETA National Seminar, 2015, pp. 697-707.

[5] N. Bafdal and S. Dwiratna, "Runoff Harvesting as One of Appropriate Technology in Integrated Dry Land Farming," in Proceedings of International Conference on Appropriate Technology Development (ICATDev) 2015, 2015, pp. 39-42.

[6] IRIS, "Autopot System - IRIS AutoPot," 2015. [Online]. Available: http://www.irisautopot.com/commercial/.

[7] R. G. Allen, L. S. Pereira, D. Raes, and M. Smith, "Crop evapotranspiration: Guidelines for computing crop requirements," Irrig. Drain. Pap. No. 56, FAO, no. 56, p. 300, 1998.

[8] U. Surendran, C. M. Sushanth, G. Mammen, and E. J. Joseph, "Modelling the Crop Water Requirement Using FAO-CROPWAT 
and Assessment of Water Resources for Sustainable Water Resource Management: A Case Study in Palakkad District of Humid Tropical Kerala, India," Aquat. Procedia, vol. 4, no. Icwrcoe, pp. 1211-1219, 2015.

[9] M. Benito, A. Masaguer, R. De Antonio, and A. Moliner, "Use of pruning waste compost as a component in soilless growing media," Bioresour. Technol., vol. 96, no. 5, pp. 597-603, 2005.

[10] W. R. Carlile, C. Cattivello, and P. Zaccheo, "Organic Growing Media: Constituents and Properties," Vadose Zo. J., vol. 14, no. 6, pp. $1-13,2015$.

[11] A. Graceson, J. Monaghan, N. Hall, and M. Hare, "Plant growth responses to different growing media for green roofs," Ecol. Eng., vol. 69, pp. 196-200, 2014.
[12] C. Steiner and T. Harttung, "Biochar as a growing media additive and peat substitute," Solid Earth, vol. 5, no. 2, pp. 995-999, 2014.

[13] R. V. \& S. C. R. Nagaraj D. M., Nemichandrappa M, Kavita K., "Effect of Different Growing Media on Quality, Growth and Yield of Bell Pepper (Capsicum Annuum Var. Grossum) Under Shade House Conditions," Int. J. Agric. Sci. Res., vol. 5, no. 4, pp. 277-284, 2015.

[14] A. Olley, "Greenhouse Tomato Production in Cocopeat Turkey,' Andrew Olley Consult., pp. 1-57, 2009.

[15] Y. Awang, A. S. Shaharom, R. B. Mohamad, and A. Selamat, "Chemical and physical characteristics of cocopeat-based media mixtures and their effects on the growth and development of celosia cristata,” Am. J. Agric. Biol. Sci., vol. 4, no. 1, pp. 63-71, 2009. 